\title{
Situacion de la Acreditación en la Facultad de Enfermería de la Universidad Nacional San Luis Gonzaga de Ica
}

Accreditation situation in the School of Nursing of the Universidad Nacional San Luis Gonzaga Ica

\author{
Mg. Mariela Pecho Tataje
}

${ }^{1}$ Decana del Consejo Regional XV del Colegio de Enfermeros del Perú - Ica, Perú.

Presidenta de Acreditación del Comité Interno de la Facultad de Enfermería de la UNICA.

\section{Sr. Editor.}

Ante la crisis de la educación superior en el mundo surgen los mecanismos de certificación y acreditación, a fin de asegurar la calidad educativa, que las instituciones deben brindar. Calidad es un componente insoslayable de toda transformación e innovación en la perspectiva del sentido hondo de todo quehacer educativo. Una institución debe tener el reto de mejorar la calidad de lo contrario sería irresponsable y el estado debe garantizar una educación con calidad.

EI SINEACE se crea en el país Según Ley 28740 en el 2006 "Ley del Sistema Nacional de Evaluación, Acreditación y Certificación de la Calidad Educativa", cuyo objetivo es: garantizar la calidad educativa a través de la evaluación y acreditación de las instituciones y la certificación de competencias de las personas y define la Acreditación como el reconocimiento público y temporal de la institución educativa, área, programa o carrera profesional que voluntariamente ha participado en un proceso de evaluación de su gestión pedagógica, institucional y administrativa, con ello se busca el aseguramiento de la calidad educativa en el país. La acreditación no es solo un instrumento para la mejora continua sino también es la fuente del saber de padres de familia y futuros estudiantes para una idónea selección del qué estudiar y dónde hacerlo. Con la primera acreditación, cuya información constituye la línea base para el posterior crecimiento en calidad, se podrá tener el mejor observatorio del cómo las universidades y los programas de estudios crecen en calidad. La Acreditación busca garantizar que las competencias profesionales de los egresados de las instituciones acreditadas sean eficientes $y$, por ende, reflejen una formación educativa de calidad.

En ese sentido la facultad de Enfermería de la ÚNICA viene trabajando desde el año 2006 uno de los pilares de la reforma de la educación superior como es el proceso de acreditación y que tiene que ver con la garantía en la calidad de la formación que se ofrece para lograr una gran transformación con una educación enfocada hacia el desarrollo del país, desde entonces y con ese horizonte hemos desarrollado el proceso ;con el modelo propuesto por CONEAU para la carrera de Enfermería desde el año 2010 con 98 estándares según el modelo que son expectativas de calidad alcanzables que debemos obtener para demostrar la calidad ,pasando por sus diferentes etapas desde la sensibilización y autoevaluación ,incluyendo un plan de mejoras, encabezado por el comité interno encargado de dirigir el proceso con camino a la acreditación sin embargo nuestro transitar ha sido muy lento pero con un gran grupo humano de docentes y trabajadores comprometidos con el cambio ,a veces débil apoyo de autoridades ;sin embargo desde el año 2012 se crea OGAYCA la oficina general de acreditación y calidad universitaria de la universidad la cual ha venido supervisando y evaluando a las carreras con exigencias de acreditación y ha desarrollado un acompañamiento a la facultad en este proceso. 
La Facultad de Enfermería de la UNICA sus autoridades y el comité interno ha venido solicitando asesoramiento acompañamiento y apoyo a entidades y grupos conocedores para superar estándares, pero es hasta el 31 de agosto que por iniciativa de OGAYCA invitan a Procalidad y nos sometemos a una pre-evaluación alcanzando un $75 \%$ de estándares aprobados para poder obtener un acompañamiento y asesoría, es así como recibimos la visita de un asesor, la Ing. Gladys Reyna Mendoza, la cual nos ha realizado 2 evaluaciones para cumplimiento de estándares logrando alcanzar el ultimo $88.5 \%$ de avanza de cumplimiento lo cual nos da la posibilidad de solicitar financiamiento para el plan de mejoras de nuestra facultad; aún nos encontramos trabajando con asesorías y esperamos llegar a la meta trazada, ser una Facultad Acreditada, declarada en nuestra visión.

Procalidad es un proyecto de inversión pública con el que cuenta el SINEACE, fortalece el sistema de aseguramiento de la calidad al fomentar la mejora financia la evaluación externa y planes de mejora para la acreditación y lograr la excelencia. Así mismo desarrolla sistemas de información en líneas visibles al estado y a la sociedad para la adopción de decisiones en calidad educativa.
La acreditación es la meta que todas las instituciones educativas deben alcanzar para garantizar una educación de calidad y una formación para la vida, promoviendo una cultura de calidad, mejora continua y el estado debe ser el garante de una educación de calidad.

Como universidad tenemos una gran responsabilidad social, acreditación tarea de todos.

Correspondencia.

Mg. Mariela Pecho Tataje.

Correo electrónico:

marielapecho_25@hotmail.com

Recibido: 17/11/2015 